\title{
ESTUDO DAS INTERAÇÕES ENTRE VISITANTES FLORAIS E PLANTAS VISITADAS, COM ENFOQUE NAS SÍNDROMES FLORAIS EM UMA ÁREA ANTROPIZADA NA BAHIA
}

\author{
Eliane da Silva Anunciação'; Miriam Gimenes ${ }^{2}$ \\ 1. Bolsista PIBIC/FAPESB, Graduanda em Licenciatura em Ciências Biológicas, Universidade Estadual de Feira de \\ Santana, e-mail: esanunciacao@ hotmail.com \\ 2. Orientadora, Departamento de Ciências Biológicas, Universidade Estadual de Feira de Santana, e-mail: \\ miriagimenes@gmail.com
}

PALAVRAS-CHAVE: Polinização; visitantes florais; síndromes de polinização.

\section{INTRODUÇÃO}

A polinização é importante para que haja a transferência do pólen (parte masculina) para o estigma (receptor feminino) da mesma flor ou de outra flor da mesma planta ou de outra planta da mesma espécie (FAEGRI \& VAN DER PIJL, 1979).

A polinização pode ocorrer através de fatores bióticos e abióticos. Dentro da polinização biótica a relação do polinizador com a planta abrange vários aspectos como morfológicos, comportamentais e temporais. Dentro dos aspectos morfológicos esperase que haja um "encaixe" entre o visitante e a flor, especialmente com relação ao contato com as estruturas reprodutivas, ocasionando a polinização. Cada flor apresenta um conjunto de características morfológicas que, de certa forma, direciona o visitante floral. Segundo Vieira \& Fonseca (2014), a morfologia e a biologia floral estão intimamente relacionadas com a polinização e reprodução. Esse conjunto de características morfológicas ou atributos florais que são comuns a determinados grupos de polinizadores é denominado como Síndrome Floral (FAEGRI \& VAN DER PIJL, 1979).

Devido à importância do conhecimento das síndromes de polinização para o entendimento da biologia reprodutiva no nível de comunidade, este trabalho teve como objetivo estudar a fauna de insetos visitantes florais, especialmente insetos e as plantas visitadas para coleta de recursos florais, com ênfase na análise das síndromes florais presentes nas espécies de planta que ocorrem em áreas antropizadas. Esse estudo contribui para o entendimento da conservação e da ecologia reprodutiva da comunidade vegetal e dos seus polinizadores em áreas antropizadas.

\section{METODOLOGIA}

O estudo foi realizado em uma área antropizada em Feira de Santana, BA (Campus da Universidade Estadual de Feira de Santana (UEFS). O Campus da UEFS possui área total de aproximadamente $1,2 \mathrm{~km} 2$, a vegetação original da área era predominantemente Caatinga de porte herbáceo-arbustivo, atualmente apresentando plantas introduzidas e invasoras (SANTANA \& SANTOS, 1999). A definição da área escolhida para a realização do trabalho foi feita logo após uma sondagem realizada no Campus da UEFS. Tendo em vista que havia uma repetição de espécimes de plantas por todo o Campus, foi decidido que a área a ser de estudo seria próximo aos Laboratórios de Biologia, Lab 0 e Museu de Zoologia, numa área de aproximadamente $800 \mathrm{~m}^{2}$.

O trabalho de campo foi realizado mensalmente durante 10 meses, de setembro de 2016 a junho de 2017. A coleta dos insetos visitantes foi feita em dois dias, das 7:00 às 17:00 h, seguindo o método adaptado de Sakagami et al, (1967). 
Para a definição de tamanho das flores que foram analisadas neste estudo foi utilizada a classificação de Machado \& Lopes (2004). Foram analisados os seguintes atributos florais $(\mathrm{N}=10)$ forma, simetria, cor e recurso floral coletado e foram feitas medidas do comprimento e diâmetro das flores e do comprimento das inflorescências, com paquímetro digital $(\mathrm{N}=10)$ por espécie de planta em indivíduos diferentes. As medidas foram feitas com o auxílio de paquímetro digital.

A identificação das cores das flores foi feita de acordo com Machado e Lopes (2004). Quanto à forma floral foi utilizada a classificação descrita em Gonçalves \& Lorenzi (2011) e Souza et al. (2013). Para análise das síndromes florais das plantas que serão encontradas no estudo será utilizada a caracterização utilizada por Faegri \& Van der Pijl, (1979).

A caracterização das unidades de polinização, bem como a organização das flores das inflorescências feitas de acordo com Ramirez et al. (1990). Foram realizadas análises da morfologia dos insetos visitantes como tamanho do corpo (do ocelo médio até o ápice do abdômen) e largura (entre as tégulas) para isso, foram realizadas com aproximadamente 10 indivíduos de cada espécie. As medidas foram realizadas com paquímetro digital.

As plantas foram identificadas em nível de família através da bibliografia (SOUZA \& LORENZI, 2012) e em nível de gênero e espécie por especialistas presentes na UEFS e literatura especializada.

\section{RESULTADOS E DISCUSSÃO}

A escolha das plantas do estudo foi feita de maneira aleatória, sendo escolhidas aquelas que estavam disponíveis no Campus no momento e no roteiro estabelecido. Assim, no geral, foram registradas espécies de plantas das famílias Asteraceae, Convolvulaceae, Fabaceae, Malvaceae, Rubiaceae, Turneraceae e Verbenaceae (Tabela 1). No entanto, as espécies Rhaphiodon echinus (Nees \& Mart.) Schauer, Turnera chamaedrifolia Cambess., Stylosanthes sp., Macroptilium Lathyroides (L.). Urb., Piriqueta sp., Stigmaphyllon sp., Evolvulus sp. Banisteriopsis sp. foram consideradas para o estudo de síndromes florais, porém não para o estudo dos visitantes por causa do serviço de capinação do Campus, sendo que as outras plantas permaneceram na área de estudo durante todo o tempo do estudo.

A maioria das plantas tive unidade de polinização individual sendo elas: $J$. bracteosa, I. bahiensis, C. sabutius, $T$. subulata, C. amiciella, H. crispa, P. cancellata e Stemodia foliosa. Nestas plantas, os visitantes tinham o comportamento de pousar diretamente sobre a flor. As plantas T. procumbens, A. fastigiatum, Mimosa sp., $L$. camara e B. verticillata foram consideradas como coletivistas. Somente $R$. grandiflora foi considerada do tipo intermediário.

Tabela 1: Lista das espécies, hábito, sexo e recurso das plantas no Campus da Universidade de Feira de Santana (UEFS) durante o período de estudo, de novembro/ 2016 a maio de 2017. (hermafrodita - herma, trepadeira- trep, subarbusto- subarb, unixessuada- unixes, pólen/ néctar- pól/ néc).

\begin{tabular}{lccc}
\hline \multicolumn{1}{c}{ Espécie } & Hábito & Sexo & Recurso \\
\hline $\begin{array}{l}\text { Asteraceae } \\
\text { Ageratum fastigiatum (Gardn.) R. M. King et H. }\end{array}$ & & & \\
Rob. & erva & unixes & pól/néc \\
Tridax procumbens Linn & erva & unixes & pól/néc \\
Convolvulaceae & & &
\end{tabular}




\begin{tabular}{|c|c|c|c|}
\hline Ipomoea bahiensis Willd. ex Roem. \& Schult & trep & herma & pól/néc \\
\hline Jacquemontia bracteosa Meisn & trep & herma & pól/néc \\
\hline Jacquemontia evolvuloides (Moric) & trep & herma & pól/néc \\
\hline \multicolumn{4}{|l|}{ Fabaceae } \\
\hline Chamaecrista amiciella (H.S.Irwin \& Barneby) & subarb & herma & pólen \\
\hline Mimosa sp. & erva & unixes & pól/néc \\
\hline \multicolumn{4}{|l|}{ Gratiolaceae } \\
\hline Stemodia foliosa Benth & subarb & herma & pól/néc \\
\hline \multicolumn{4}{|l|}{ Malvaceae } \\
\hline Herissantia crispa (L.) Brizicky & erva & herma & pólen \\
\hline Pavonia cancellata (L.) Cav. & erva & herma & pól/néc \\
\hline \multicolumn{4}{|l|}{ Rubiaceae } \\
\hline Borreria verticillata (L.) G.Mey. & subarb & herma & pól/néc \\
\hline Richardia grandiflora (Cham. \& Schltdl.) Steud. & erva & herma & pól/néc \\
\hline \multicolumn{4}{|l|}{ Verbenaceae } \\
\hline Lantana camara L. & subarb & herma & néctar \\
\hline \multicolumn{4}{|l|}{ Turneraceae } \\
\hline Turnera subulata Smith & subarb & herma & pól/néc \\
\hline
\end{tabular}

Os atributos florais observados para o conjunto de espécies de plantas estudas variou bastante no quesito cor das flores, no qual foi considerado que estas flores possuem cores bastante vistosas. As flores amarelas foram as mais frequentes, seguidas das flores rosa claro. O estudo de Machado \& Lopes (2004) com recursos florais e sistemas de polinização e sexuais em três áreas da caatinga localizadas na zona rural do Estado de Pernambuco, também registrou uma maior frequência de flores amarelas (25\%).

A maioria das flores das espécies de plantas foi considerada actinomorfa (simetria radial) $(66,67 \%)$ e as demais flores foram consideradas zigomorfas (simetria bilateral) $(33,33 \%)$. Machado \& Lopes (2004) também registraram uma frequência maior das espécies radias com $61,7 \%$ das flores e bilaterais com $38,3 \%$.

A presença de odor foi observada em $28,57 \%$ das flores, sendo que $19,05 \%$ das flores apresentavam um odor fraco e 52,38\% das flores do estudo não apresentavam cheiro. A maioria das flores não possui guia de néctar $(57,14 \%)$ e $42,86 \%$ das flores possuem guia de néctar.

As espécies Mimosa sp., B. verticillata, T. procumbens, A. fastigiatum, Stemodia foliosa e L. camara foram consideradas de tamanho pequeno, pois estas plantas tiveram medidas menor que $10 \mathrm{~mm}$. Chamaecrista sp., Convolvulus sp., H. tiubae e $R$. grandiflora foram consideradas com tamanho médio e I. bahiensis, J. bracteosa, P. cancellata e $T$. subulata foram consideradas muito grandes, pois estas flores mediram acima de $30 \mathrm{~mm}$. No estudo de Machado e Lopes (2004) a maioria das plantas apresentaram flores com tamanho grande $(54,1 \%)$, seguida por de flores muito grandes $(43 \%)$, flores pequenas $(23,7 \%)$ e médias (22,2\%). De acordo com Opler (1980 apud Machado \& Lopes, 2004), de forma geral o tamanho das flores está associado aos polinizadores florais.

A síndrome de polinização mais frequente nas espécies de planta no campus da UEFS foi a melitofilia, ocorrendo em 42, 86\% espécies estudas, seguida pela psicofilia ocorrendo em $38,10 \%$ das espécies de plantas. Algumas plantas foram consideradas com os dois tipos de síndromes (melitofilia e psicofilia), ocorrendo em 19,05\% das plantas. No estudo de Santos et al. (2009) sobre as síndromes de polinização em um fragmento urbano de Mata Atlântica secundária da cidade de Salvador, BA, foi observado que a 
síndrome de polinização mais frequente foi a anemofilia, ocorrendo em 16,2\% das espécies estudadas, seguidas pela psicofilia $(12,1 \%)$, pela cantarofilia $(9,1 \%)$, pela miiofilia e ornitofilia $(6,1 \%)$, a falenofilia e quiropterofilia ocorreram em menos de $5 \%$ das plantas estudadas.

No geral, as espécies de plantas foram visitadas por abelhas Apis mellifera (Lepeletier), Ceratina (crewella) spp., Melitoma segmentaria (Fabricius), Trigona spinipes (Fabricius), Augochlora sp. 1, Augochlora sp.2, Pseudaugochlora sp. 2 e por borboletas Pyrgus orcus (Stoll), Pyrgus vuturius (Plötz), Urbanus dorantes (Stoll), Hemiargus hanno (Stoll), Agraulis vanillae (Linnaeus), Anartia jatrophae (Linnaeus), Battus ethilla narcaea (Godart), Heliconius erato phyllis (Fabricius), Phoebs sennae (Linnaeus). A maioria das espécies de abelhas foi considerada pequena, pois estas apresentavam o comprimento menor que $10 \mathrm{~mm}$ e largura menor que $2,4 \mathrm{~mm}$ e a maioria das borboletas tiveram tamanho médio intermediário.

\section{CONCLUSÃO}

As síndromes de polinização são importantes para o entendimento das interações entre as plantas e os visitantes florais. A melitofilia foi a síndrome mais frequente das espécies de plantas encontradas no Campus da UEFS no período de estudo. O que indica que as abelhas são os principais visitantes florais presentes na área no Campus da UEFS, especialmente espécies pertencentes às famílias Apidae, Halictidae (abelha), Hisperidae, Lycaenidae, Lycaenidae, Nymphalidae, Pieridae também foram registadas visitando as flores das plantas na área estudada.

\section{REFERÊNCIAS}

FAEGRI, K.; VAN DER PIJL, L. The principles of pollination ecology. London, Pergamon Press, 244 p., 1979.

GONÇALVES, E. G.; LORENZI, H. Morfologia Vegetal: Organografia e Dicionário Ilustrado de Morfologia das Plantas Vasculares. São Paulo: Instituto Plantarum de Estudos da Flora, ed. 2, 512 p., 2011.

MACHADO, I. C.; LOPES, A. V. Floral traits and pollination systems in the Caatinga, a brazilian tropical dry forest. Annals of Botany, (94) 365-376, 2004.

RAMIREZ, N.; GIL, C. HOKCHE, O; SERES, A.; BRITO, Y. 1990. Biologia floral de uma comunidad arbustiva tropical em La Guayana Venezolana. Annals of the Missouri Botanical Garden (77) 383-397, 1990.

SAKAGAMI, S.F., LAROCA, S. \& MOURE, J.S. 1967. Wild bee biocenotics in São José dos Pinhais (PR), South Brazil. Preliminary report. Journal Faculty of Hokkaido University, n. 19, p. 190-250, 1967.

SANTANA, J.R.F.; SANTOS, G.M.M. 1999. Arborização do campus da UEFS: um exemplo a ser seguido ou um grande equívoco? Sitientibus, 20, 103-107, 1999.

SANTOS, M. F. O.; QUEIROZ, E. P.; PIGOZZO, C. M. Síndromes de polinização em fragmento urbano de Mata Atlântica do $19^{\circ}$ Batalhão de Caçadores, Cabula, Salvador, Bahia. Candombá, Revista Virtual, 5 (1) 26-39, 2009.

SOUZA, V. C.; FLORES, T. B.; LORENZI, H. Introdução à Botânica: Morfologia. São Paulo: Instituto Plantarum de Estudos de Flora, 223 p., 2013.

VIEIRA, M. F.; FONSECA, R. S. Biologia reprodutiva em angiospermas: síndromes florais, polinizações e sistemas reprodutivos sexuados. Viçosa, MG, ed. 577, (3) 8-11, 2014. 